\title{
The Effect of New Energy Vehicle Policies on Traffic Congestion: Evidence from Beijing
}

\author{
Xuenan $\mathrm{Ju}^{1}$, Baowen $\mathrm{Sun}^{2}$ \& Jieying $\mathrm{Jin}^{3}$ \\ ${ }^{1}$ Assistant Professor, China Centre for Internet Economy Research, Central University of Finance and Economics, \\ Beijing, China \\ ${ }^{2}$ Professor, China Centre for Internet Economy Research, Central University of Finance and Economics, Beijing, \\ China \\ ${ }^{3}$ Central University of Finance and Economics, Central University of Finance and Economics, Beijing, China \\ Correspondence: Xuenan Ju, Assistant Professor, China Centre for Internet Economy Research, Central University of \\ Finance and Economics, Beijing, China. E-mail: juxn.10@sem.tsinghua.edu.cn
}

Received: September 11, 2018

Accepted: October 11, 2018

Online Published: October 22, 2018

doi:10.5430/bmr.v7n4p9

URL: https://doi.org/10.5430/bmr.v7n4p9

\begin{abstract}
Objective: This paper systematically summarizes Beijing's new energy vehicle (NEV) policies (including lottery policy and driving-restriction policy) and investigates their impacts on traffic congestion. We propose that although the current NEV policies might alleviate air pollution by reducing exhaust emission, they could worsen Beijing's traffic condition by increasing congestion probability.
\end{abstract}

Methods: We adopted general traffic flow model and TTI congestion probability model to conduct empirical analysis. In addition, we also simulate NEV policies with different settings (\% of NEVs and the degree of driving restrictions).

Results: Empirical findings based on Beijing's traffic data show that the higher the proportion of newly added NEV is, the larger the congestion probability will be, which support our proposition.

Conclusions: Research results indicate that the lottery policy increases the proportion of NEVs in the total number of newly-added vehicles. Moreover, as the NEVs are not subjected to driving-restriction policy, the number of vehicles travelling on the road will increase and the average velocity will decrease. Hence, traffic congestion is more likely to happen. Finally, policy implications and future research directions are also discussed.

Keywords: new energy vehicle (NEV), NEV policies, traffic congestion, Beijing traffic, lottery policy, driving restriction policy

\section{Introduction}

With the acceleration of urbanization and rapid economic development, many Chinese cities frequently suffer from air pollution in recent years. Beijing is one of the most haze-polluted regions in China. In 2015, the mean annual density of fine particulate matter smaller than $2.5 \mu \mathrm{m}\left(\mathrm{PM}_{2.5}\right)$ in Beijing was 80.6 microgram $/ \mathrm{m}^{3}, 1.3$ times as much as the national standard (Note 1).

Recent researches indicate that traffic has become an important source of Beijing's air pollution (Huang et al., 2014; He et al., 2012). According to Beijing Municipal Environmental Protection Bureau, motor vehicle exhaust accounts for $40 \%-60 \%$ of suspended particulates, $80 \%$ of hydrocarbons, $70 \%-80 \%$ of $\mathrm{NO}_{\mathrm{x}}$, and $23 \%$ of $\mathrm{PM}_{10}$. Liu et al. (2009) estimate that motor vehicles are the second largest source of $\mathrm{PM}_{2.5}$.

To address air quality concerns, Beijing has been vigorously implementing a series of administrative policies to control vehicle emission. Table 1 summarizes traffic-related policies implemented by Beijing government in order to improve air quality. 
Table 1. Beijing's traffic-related policies in pursuing for better air quality

\begin{tabular}{llll}
\hline Policies & Goals & Detail \\
\hline 1 & $\begin{array}{l}\text { Driving } \\
\text { restriction }\end{array}$ & Limit the number of cars on roads & $\begin{array}{l}\text { Cars could not drive on Beijing roads for one weekday } \\
\text { each week, depending on the last digit of the license } \\
\text { plate number. }\end{array}$ \\
2 Lottery policy & $\begin{array}{l}\text { Restrict the total number } \\
\text { vehicles }\end{array}$ & $\begin{array}{l}\text { Lottery system for new car license plates; Keep the } \\
\text { number of cars under } 6.3 \text { million by the end of 2020 by } \\
\text { further tightening the annual quota for license plates. }\end{array}$ \\
\hline
\end{tabular}

Meanwhile, Beijing is actively promoting the generalization of new energy vehicles (NEVs) by loosening these restrictions. First, the NEVs are not constraint by license plate restriction and they can drive on daily bases. As of the lottery policy, NEVs have higher probability to win a new license plate compared to gasoline vehicles. From 2011 to 2017, the proportion of NEVs in the planned annual quota is rising from $0 \%$ to $40 \%$.

On the other hand, Beijing has also been recognized as one of the most congested cities in the world due to the growing fleet of motor vehicles. By the end of 2015, the number of vehicles owned in Beijing was more than 5.6 million. The traffic volume is huge and traffic congestion is severe, especially during morning/evening rush hours.

Beijing's traffic congestion has large and growing costs. Xie et al. (2011) estimated that the costs of time delay, fuel consumption, and air pollution were between 5 and 25 billion RMB in 2008, about $0.5 \%$ to $2.5 \%$ of Beijing's annual GDP. Moreover, the emission volume escalates during traffic congestion. Therefore, both the growing number of motor vehicles and the worsening traffic condition exacerbate problems of Beijing's air pollution.

In this paper, we question the NEV policies' effects on Beijing's traffic condition. First, the number of NEVs and its proportion in total vehicles will increase due to the lottery policy. Second, since driving restriction policies are not applicable to the NEVs, the increment of NEVs will result in more vehicles on Beijing's road network. Consequently, more vehicles on roads will ratchet up traffic pressure, slow down the velocity of vehicles on the road network, hence, increase the probability of congestion.

By adopting general traffic flow model and TTI congestion probability model, this paper (1) theoretically depicts the mechanism of NEV policies' impact on traffic congestion; (2) empirically evaluates the impacts of NEV policies on traffic congestion; and (3) stimulates different settings of NEV policies and explores their impacts on traffic congestion respectively. The empirical study is based on the actual traffic data from 2010-2016 in Beijing Municipality.

\section{Literature Review}

\subsection{Traffic Flow and Congestion}

Researches concerning traffic flow and congestion models began in 1930. After entering the 1990s, with the rapid growth of traffic demand and technical progresses, traffic congestion has received more and more attention. Treiber et al. (2013) have classified the existing traffic flow models by aggregation level, mathematical structure and other criteria. Bando et al. (1995) and Zhao et al. (2005) simulated the occurrence and transmission of traffic congestion based on improvements to the typical traffic dynamics model. Pasquale et al. (2015) and Hoshino et al. (2011) explored methods to control and relieve traffic congestion. Horvitz et al. (2012) and Wang et al. (2015) attempted to use models to predict traffic flow and traffic congestion in certain areas.

To make the best use of a traffic flow model for quantification and prediction to traffic congestion, scholars have proposed the concept of "probability of traffic congestion" and applied it to intelligent traffic navigation systems. For instance, Cui (2015) estimated the probability of traffic congestion in urban areas with a cumulative logistics model. Liu and Liu (2015) suggested a Bayesian approach to analyze the congestion probability on urban road networks. Zhang (2015) introduced vehicle travel time index (TTI) and designed a model where the parameters of the probability distribution model for TTI vary with sectional velocity.

\subsection{Traffic and Air Pollution}

With the development of economy and urbanization process, air pollution increasingly attracts attention for health and safety issues (Guo, 2017). Since air pollution is closely related to exhaust emissions from gasoline vehicles, especially during the congestion period, existing studies are highly concerned with the relationship between traffic and air pollution. Air pollution in Beijing is characterized as photochemical smog and dust-haze, which come from industrial pollution and the formation of secondary aerosols (Guo et al., 2014). Ground traffic is the major source to 
produce volatile organic compounds (VOCs) and nitrogen oxides $\left(\mathrm{NO}_{\mathrm{x}}\right)$, which are the raw materials of secondary aerosols. In addition, motor vehicles also emit massive amounts of carbon monoxide $(\mathrm{CO}), \mathrm{NO}_{\mathrm{x}}$, and $\mathrm{VOC}_{\mathrm{s}}$, worsening Beijing's air quality directly (Yang et al., 2014). Therefore, traffic has become an important source of Beijing's air pollution (Huang et al., 2014).

\subsection{Congestion-Control Policies}

With traffic congestion becoming increasingly aggravated, different traffic policies are put forward to relieve the strain on traffic worldwide. Identical with Beijing, Athens and Mexico City also adopt driving restriction policy to alleviate traffic pressure. Meantime, there are other transportation policies that could reach the similar effect. For instance, Singapore and Tehran introduced congestion charging and expanded public transportation system. Increasing parking fee and hourly parking during congested period is another approach that adopted by megacities in order to control traffic flow in town (Munford, 2017). Since traffic control and congestion is a complex system with dynamic nature, academic studies often adopt system dynamics to depict and predict traffic flow and congestion probability. Xu (2014), Zhang et al. (2015), Liu and Liu (2015) use the system dynamics model to explore the effective intervention of traffic policies among the number of vehicles owned, traffic conditions, and vehicle pollutant emissions.

Although traffic congestion and air pollution are two trending themes that raising incredible attention in recent years, comprehensive research that combines these two topics has not yet reached maturity. This gap is especially salient in NEV policies, which is our research subject. In recent years, NEV studies concentrate on consumer evaluation and intention (Graham-Rowe et al., 2012; Schuitema et al., 2013), marketing segmentation (Campbell et al., 2012; Brand et al., 2017) and infrastructure (Li et al., 2017) perspectives. However, researches that evaluate NEV policies from their impact on traffic congestion is scarce. In addition, since vehicle exhaust escalates during congestion period, NEV polices might even worsen Beijing's air quality, despite the original expectations. Therefore, it is both necessary and urgent to investigate NEV policies' impact on traffic congestion.

\section{Theoretical Framework}

This paper investigates the effects of NEVs on traffic congestion. As abovementioned, lottery policy and license restriction policy are closely related to NEVs' popularization. While lottery policy result in the increasing number of NEVs, driving restriction policy leads to the growth in the number of vehicles driving on the road network, which might worsen traffic conditions. Figure 1 shows the conceptual model in detail. 
NEV Policies Key variables Process Mechanism

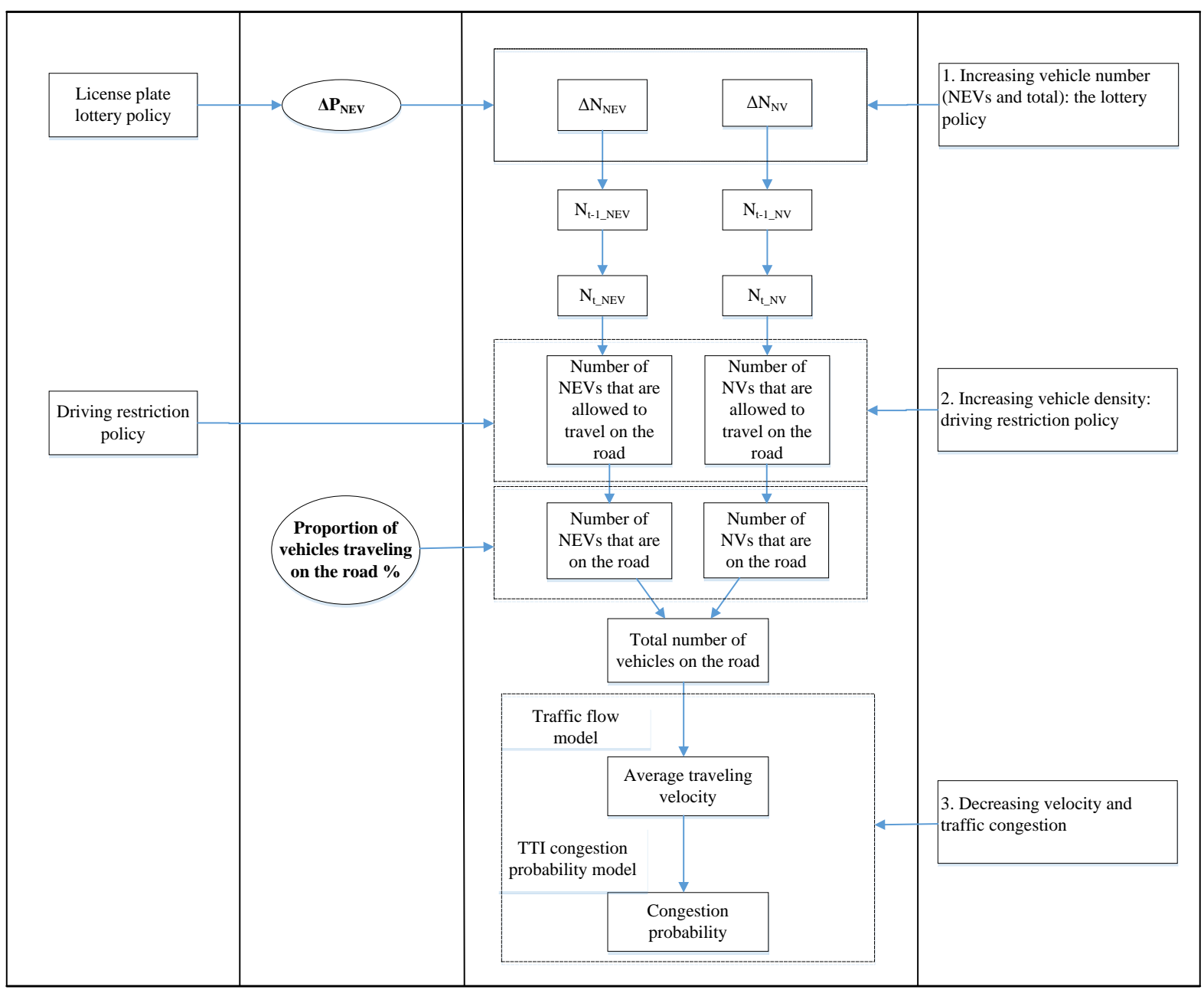

Figure 1. Conceptual model

Before discussing our conceptual model, we first make two assumptions:

Assumption 1: the average motor vehicle scrap in Beijing from 2013 to 2015 is 40,000 each year, accounting for $0.72 \%$ of the total vehicles, which is negligible compared to key variables in our model. Therefore, the amount of vehicle scrap is ignored (see appendix 1).

Assumption 2: although there are four types of NEVs (pure electric, fuel cells, hybrid and plug-in hybrid) in the market, Beijing's NEV policies are only applicable to pure electric vehicles (EV) (Note 2). Hence, in this paper NEV refers in particular to pure electric vehicles.

Our conceptual model consists of three parts, including the increase of vehicle numbers, the increase of vehicle density on the road network, and the cause of traffic congestion as a result of decreasing speed, respectively.

\subsection{Increasing Vehicle Number (NEVs and Total): The Lottery Policy}

As summarized in Table 2, Beijing's lottery policy has two main effects:

First, although the total vehicle number in Beijing keeps growing in recent years, the lottery policy has slowed the speed of car parc growth by controlling the annual quota of newly added cars and this quota is shrinking from 240 thousand to 150 thousand since 2014.

Second, the lottery policy significantly changes the component ratio of Beijing's vehicle increments. Despite the shrinking of annual quota, the NEVs proportion is increasing from 0 to $40 \%$ during last 5 years.

Therefore, we can observe the increase of NEV numbers both in scale and growth in Beijing. In addition, as the 
policy orientation of promoting NEVs remains, we can predict further development of NEVs in the predictable future.

Table 2. Composition of lottery policy (annual newly increased motor vehicles) in Beijing from 2011-2017 (10,000 vehicles) (Note 3)

\begin{tabular}{|c|c|c|c|c|}
\hline Year & $\begin{array}{l}\text { Gasoline } \\
\text { vehicles }\end{array}$ & NEVs & $\begin{array}{l}\text { Annual newly added } \\
\text { vehicles }\end{array}$ & Proportion of NEVs (\%) \\
\hline 2011 & 24 & 0 & 24 & $0 \%$ \\
\hline 2012 & 24 & 0 & 24 & $0 \%$ \\
\hline 2013 & 24 & 0 & 24 & $0 \%$ \\
\hline 2014 & 13 & 2 & 15 & $13 \%$ \\
\hline 2015 & 12 & 3 & 15 & $20 \%$ \\
\hline 2016 & 9 & 6 & 15 & $40 \%$ \\
\hline 2017 & 9 & 6 & 15 & $40 \%$ \\
\hline
\end{tabular}

\subsection{Increasing Vehicle Density: License Restriction Policy}

Furthermore, under the influence of driving restriction policies, gasoline vehicles could not drive on Beijing roads for one weekday each week, depending on the last digit of the license plate number. However, NEVs are not subject to the driving restriction policy. In addition, as the number of newly added NEVs increases, the total number of vehicles traveling on the road will increase. Hence, the current NEV policies will increase the vehicle density on Beijing's traffic network.

\subsection{Decreasing Velocity and Traffic Congestion}

According to the general traffic flow model, when the number of vehicles traveling on the road increases and the density of the traffic flow on the road network increases, the average velocity of vehicles will decrease and the probability of congestion will increase (as shown in the third part of conceptual model). When building the empirical model, this paper calculates the proportion of vehicles traveling on the road based on Beijing's traffic data. Meanwhile, we estimate the average velocity on Beijing's road network through the general traffic flow model. In the following step, we estimate the congestion probability of Beijing's road networks through the congestion probability model based on Travel Time Index (TTI).

\section{Empirical Study}

Based on the general traffic flow model and TTI-based congestion probability model, this paper calculates the average velocity on the road network and congestion probability using Beijing's actual traffic data. Furthermore, using 2015 data as baseline, we simulate Beijing's traffic conditions of the road network with different NEV policy settings.

The popularization of NEVs that are not subject to driving restrictions will increase the number of vehicles traveling on the road, slow down the speed of ground traffic. The lower the velocity is, the higher probability of traffic congestion. In the following step, we quantify the effects of the NEV policies on traffic conditions through the general traffic flow model and TTI-based congestion probability model.

As shown in the second part of our conceptual model, the number of vehicles that 'allowed' on the road are not equal to the number of vehicles that 'actually drive' on the road. In fact, only a proportion of vehicles that can travel will actually travel on the road. Therefore, the first step of our empirical study is to determine this proportion based on Beijing's traffic statistics.

\subsection{Determination of the Proportion of Vehicles Traveling on the Road}

We calculate the proportion of vehicles traveling on the road (PT) based on 2015 data and assume that the PT remains stable during the research period. The proportion of vehicles traveling on the road is calculated through the following formula:

$$
P T=\frac{N T R_{t}}{N A T R_{t}}
$$




$$
\begin{gathered}
N A T R_{t}=N_{t_{-} N E V}+0.8 \times N_{t_{-} \mathrm{NV}} \\
N T R_{t}=K_{t} \times L_{t} \\
K_{t}=K_{j} \times\left(1-V_{t} / V_{f}\right) \\
N_{t}=N_{t_{-} N E V}+N_{t_{-} \mathrm{NV}}
\end{gathered}
$$

Where, $N T R_{t}$ and $N A T R_{t}$ are the number of vehicles and the number of vehicles that are allowed to travel on the road within the observed period, respectively; $K_{t}$ is the density of vehicles on the road within the observed period; $L_{t}$ is the total length of all roads in Beijing within the observed period; $K_{j}$ is the maximum density of vehicles on the road. $V_{t}$ is the average velocity on the road network at morning peaks within the Fifth Ring Road in Beijing within the observed period; and $V_{f}$ is the velocity of the free flow in a road section. Under the current driving

\begin{tabular}{|c|c|}
\hline Parameters & Quantity \\
\hline Velocity of free flow $V_{f}(\mathrm{~km} / \mathrm{h})($ Note 4$)$ & 47.33 \\
\hline $\begin{array}{l}\text { Average velocity on the road network at morning peaks within the Fifth Ring Road in Beijing within } \\
\text { the base period } V_{t}(\mathrm{~km} / \mathrm{h})(\text { Note } 5)\end{array}$ & 28.10 \\
\hline Maximum achievable density on the road network $K_{j}($ vehicles $/ \mathrm{km})$ (Note 6) & 200 \\
\hline Density of the road network within the base period $K_{t}$ (vehicles $\left./ \mathrm{km}\right)$ & 81.27 \\
\hline Length of roads within the base period $L_{t}(\mathrm{~km})($ Note 7$)$ & 29069 \\
\hline Number of vehicles traveling on the road within the observed period $N T R_{t}(10,000$ vehicles $)$ & 236.24 \\
\hline Vehicle ownership number within the base period $\mathrm{N}_{t}$ (10,000 vehicles) (Note 8) & 561.9 \\
\hline Number of new energy vehicles within the base period $N_{t_{-} N E V}(10,000$ vehicles) (Note 9$)$ & 5 \\
\hline $\begin{array}{l}\text { Number of vehicles that are allowed to travel on the road within the base period } N A T R_{t}(10,000 \\
\text { vehicles) }\end{array}$ & 450.52 \\
\hline Proportion of vehicles traveling on the road PT & $52.44 \%$ \\
\hline
\end{tabular}
restriction policies in Beijing, this paper assumes that only $80 \%$ of gasoline vehicles are allowed to travel on the road on workdays. Table 3 summarizes specific parameters for PT calculation.

Table 3. Key parameters in calculating the proportion of vehicles traveling on the road

Table 3 shows that the proportion of vehicles traveling on the road in Beijing is $52.44 \%$. We use this PT rate for the following analysis.

\subsection{Determination of the Average Velocity Based on General Traffic Flow Model}

In the second part of empirical analysis, we adopt general traffic flow model and Beijing's traffic data to calculate the average velocity of Beijing's road network.

$$
V_{t}=V_{f} \times\left(1-K_{t} / K_{j}\right)
$$

Again, $V_{t}$ is the average velocity on the road network at morning peaks within Beijing's Fifth Ring Road within the observed period; and $V_{f}$ is the velocity of the free flow in a road section. $K_{t}$ is the density of vehicles on the road within the observed period. Taking PT into consideration, we can calculate the actual vehicle density through equation 7.

$$
K_{t}=\frac{N T R_{t}}{L_{t}}=\frac{N A T R_{t} \times P T}{L_{t}}
$$




\subsection{Determination of the Congestion Probability through the TTI-Based Congestion Probability Model}

We employ the concept of "congestion probability" to better describe the relationship between velocity and traffic congestion. This paper employs floating car data and introduces the Travel Time Index (TTI) for modeling vehicle velocity (v). The TTI refers to the ratio of the actual time spent to the smooth time (free flow) spent for traveling the same distance, which is usually obtained through velocity. Existing studies show that TTI distribution is similar to the asymmetric Gaussian distribution which obeys lognormal distribution.

Let the TTI of vehicles be $z=\frac{v_{f}}{v}$, and

$$
z \square \ln \left(\mu, \sigma^{2}\right)
$$

A maximum likelihood estimation is carried out for parameters $\mu$ and $\sigma^{2}$ :

$$
\widehat{\mu}=\frac{1}{N} \sum_{i=1}^{N} \ln z_{i} \quad \hat{\sigma}^{2}=\frac{1}{N} \sum_{i=1}^{N}\left(\ln z_{i}-\frac{1}{N} \sum_{i=1}^{N} \ln z_{i}\right)^{2}
$$

The TTI probability distribution of vehicles varies with vehicle velocity, while vehicle velocity varies with traffic loads. In this paper, traffic loads are reflected by the number of vehicles traveling on the road. According to Zhang $e t$ al. (2015), taking road section 19594 as an example in this paper (the south-to-north 19594 road section of the West $2^{\text {nd }}$ Ring in Beijing), $\hat{\mu}$ and $\hat{v}$ as well as $\hat{\sigma}^{2}$ and $\hat{v}$ can be fitted with the following function:

$$
\widehat{\mu}=a \log \widehat{v}+b \quad \widehat{\sigma}^{2}=c e^{d \bar{v}}
$$

Where the vector $\mathrm{u}=[\mathrm{a}, \mathrm{b}, \mathrm{c}, \mathrm{d}]$ is the TTI dynamic distribution feature vector of a road section, reflecting the TTI probability distribution changing with the velocity on the road section, and traffic flow variance distribution changing with dynamic in traffic loads. In addition, study also indicates that although each road section has a unique feature vector, the parameters do not vary significantly. Therefore, we simulate the average probability density distribution function of the TTI of the West $2^{\text {nd }}$ Ring, and adopt this function as the average probability density distribution function of the TTI of vehicles on different road sections in Beijing.

Let the corresponding CDF function of the probability density function $p(\mathrm{z})$ of a region be $P(\mathrm{Z})$, and the congestion threshold $\mathrm{h}(\mathrm{h}=1.5$ in this paper) is determined according to whether there is congestion on a road, then the congestion probability can be obtained through the following equation:

$$
P=1-\mathrm{P}(\mathrm{h})
$$

\section{Results}

\subsection{Empirical Results}

By adopting the TTI model, we obtained the traffic congestion probabilities based on Beijing's traffic data. Empirical results are summarized in Table 4.

Table 4. NEV proportion, vehicle number, road density, velocity and congestion probabilities

\begin{tabular}{lllllll}
\hline Years & $\begin{array}{l}\text { Proportion of } \\
\text { newly added } \\
\text { new energy } \\
\text { vehicles (\%) }\end{array}$ & $\begin{array}{l}\text { Number of vehicles } \\
\text { that are allowed to } \\
\text { travel on the road } \\
(10,000 \text { vehicles) }\end{array}$ & $\begin{array}{l}\text { Density of the road } \\
\text { network } \\
\text { (vehicles/km) }\end{array}$ & $\begin{array}{l}\text { Average } \\
\text { velocity } \\
(\mathrm{km} / \mathrm{h})\end{array}$ & $\begin{array}{l}\text { Congestion } \\
\text { probability (\%) }\end{array}$ \\
\hline 2014 & $13 \%$ & 447.68 & 80.37 & 28.31 & $19.82 \%$ \\
2015 & $20 \%$ & 450.52 & 81.27 & 28.10 & $20.55 \%$ \\
2016 & $40 \%$ & 463.72 & 82.76 & 27.75 & $21.77 \%$ \\
2017 & $40 \%$ & 476.92 & 84.58 & 27.32 & $23.31 \%$ \\
\hline
\end{tabular}

From 2014 to 2017, as the proportion of newly added NEVs increases from 13\% to 40\%, the number of vehicles that are allowed to travel on the road increases from 4.4768 million to 4.7692 million, and the density of the road network 
increases from 80.37 vehicles $/ \mathrm{km}$ to 84.58 vehicles $/ \mathrm{km}$. Consequently, the average velocity decreases from 28.31 $\mathrm{km} / \mathrm{h}$ to $27.32 \mathrm{~km} / \mathrm{h}$, and the congestion probability rises from $19.82 \%$ to $23.31 \%$. Therefore, the NEV policies do increase congestion probabilities in Beijing. Hence, our proposition is supported.

\subsection{Elasticity Analysis}

In order to better describe NEV policies' impact on traffic condition, we also conducted elasticity analysis based on the latest available data. Elasticity is an economic term, which describes the responsiveness of a variable to another. In our study, we aim to quantify the elasticity by calculate the ratio of $1 \%$ change of NEV proportion (in the total vehicles) to the percentage change in average velocity (figure 2) and congestion probability (figure 3).

Figure 2 depicts the elasticity analysis between NEV proportion and average velocity. The results show that $1 \%$ increase in the proportion of newly increased NEVs will reduce the average velocity of vehicles travelling on the road by $0.1267 \mathrm{~km} / \mathrm{h}$. Figure 3 describes congestion probability's elasticity response to the proportion of NEVs. As the result shows, $1 \%$ increase in the proportion of newly increased NEVs will increase the congestion probability by $0.45 \%$. Thus, the current NEV policies do lead to reduced velocity and more congested traffic.

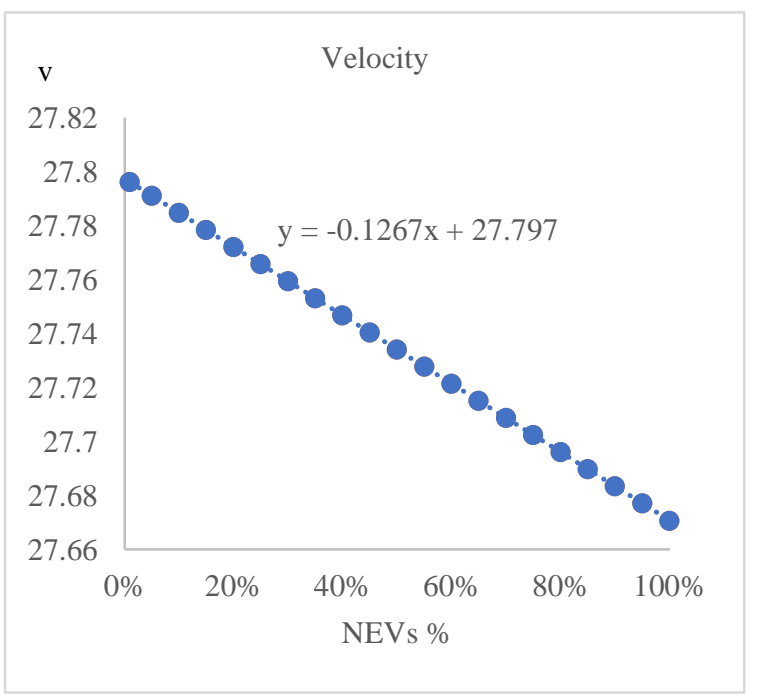

Figure 2. Elasticity analysis of NEV\% and velocity (v)

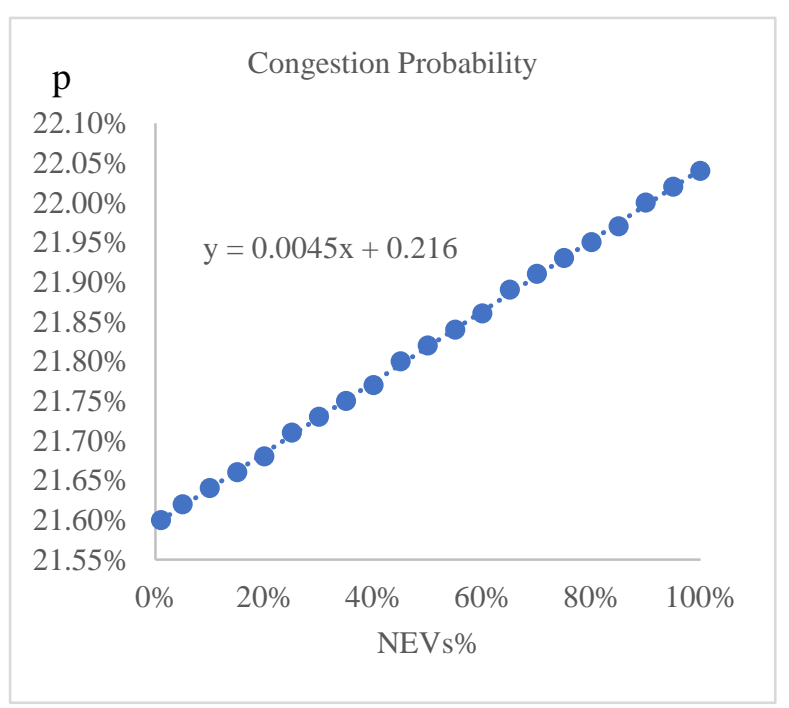

Figure 3. Elasticity analysis of NEV and congestion probability

\subsection{Effectiveness Check}

To prove the effectiveness of our model, we compared our empirical results to Beijing's officially-published traffic data (Beijing Transport Annual Report 2015). The average velocity in the report was $28.90 \mathrm{~km} / \mathrm{h}$, which confirms that our results is close to reality and the empirical model is effective.

Empirical results also indicate that the impact of the current NEV policy on traffic congestion will escalate gradually over time.

In order to verify the feasibility of our study, we compared this threshold $(26.4 \mathrm{~km} / \mathrm{h})$ to relevant policies in the Beijing Municipal Transportation Development and Construction Planning in the period of 13th Five-Year Plan (the $13^{\text {th }}$ plan). According to the $13^{\text {th }}$ Plan, the total vehicle number will be controlled within $6,300,000$ in Beijing by the end of 2020 and a one-hour urban traffic circle will be established. According to the current level of road construction, on the condition that the planned goals of the $13^{\text {th }}$ Plan could be fulfilled, we have calculated the proportion of NEVs by the end of 2020 with the model established above. The minimum velocity is settled at 26.4 $\mathrm{km} / \mathrm{h}$, which is assumed as the lowest tolerable limit velocity within the Fifth Ring of Beijing in morning peaks according to current traffic standard (Note 10). Thus, in this part we aim to find that how long it will take to reach the lowest-tolerable velocity $(26.4 \mathrm{~km} / \mathrm{h})$ if the current $\mathrm{NEV}$ policy continues. 
Table 5. Key parameters for effectiveness check

\begin{tabular}{ll}
\hline Parameters & Quantity \\
\hline Tolerable limit average velocity in morning peaks V $(\mathrm{km} / \mathrm{h})$ & 26.4 \\
Tolerable limit density $\mathrm{K}^{*}($ vehicle per $\mathrm{km})$ & 88.45 \\
Length* of road in $2020(\mathrm{~km})$ & 30122.2 \\
Number of vehicles travelling on the road in 2020 N* (million vehicles) & 266.43 \\
Number of vehicles that are allowed to travel on the road in 2020 $\mathrm{N}^{*}$ (million vehicles) & 508.11 \\
Proportion of new energy vehicles as of the end of 2020 & $3.26 \%$ \\
Number of newly added new energy vehicles from 2016 to 2020 (million vehicles) & 20.54 \\
Time calculated based on 60,000 newly added new energy vehicles per year & 3 years \\
\hline
\end{tabular}

Table 5 shows that, by adopting our empirical model, after three years (until 2020), Beijing's traffic in morning peaks would be severely congested and unbearable for daily commute. Thus, if the current NEV policy continues (with $60,000 \mathrm{NEVs}$ added every year), the time window resulted in our model coincides with the $13^{\text {th }}$ plan, which claims to control the total vehicle number under 6,300,000 in Beijing by the end of 2020. Therefore, our model is feasible and effective for practical implications.

\section{Policy Simulation}

Adopting the current model, we can also conduct policy simulations. Thus, in this part we will investigate NEVs' impacts on traffic condition under different policy settings. Specifically, ceteris paribus, we can stimulate different levels of lottery policy (\% of NEVs) and the driving restriction policy (number of vehicles on road) and investigate their impacts on traffic congestion. Here we use the latest available data (2016) as the policy simulation study.

\subsection{Simulation on the Lottery Policy}

We provide three settings for the lottery policy, with the proportion of the newly-added NEVs in the total newly-added vehicles are 0 (policy 1), 40\% (policy 2, the current policy), and 100\% (policy 3), respectively. Table 6 shows that with an increase of newly added NEVs and its proportion in Beijing's total vehicles (from policy 1 to policy 3 ), the congestion probability of Beijing's road network rises from $21.59 \%$ to $22.04 \%$. Hence, the more newly added NEVs in the total vehicle increments, the higher the congestion probability will be.

Table 6. Traffic congestion probabilities under different lottery policies

\begin{tabular}{lllll}
\hline Policies & $\begin{array}{l}\text { Number of newly } \\
\text { added new energy } \\
\text { vehicles }(\mathbf{1 0 , 0 0 0 )}\end{array}$ & $\begin{array}{l}\text { Number of newly added } \\
\text { traditional } \\
\text { vehicles }(\mathbf{1 0 , 0 0 0 )}\end{array}$ & $\begin{array}{l}\text { Average velocity } \\
\text { energy }\end{array}$ & $\begin{array}{l}\text { Congestion } \\
\text { probability }(\%)\end{array}$ \\
\hline Lottery Policy 1 & 0 & 15 & 27.80 & 21.59 \\
Lottery Policy 2 & 6 & 9 & 27.75 & 21.77 \\
Lottery Policy 3 & 15 & 0 & 27.67 & 22.04 \\
\hline
\end{tabular}

6.2 Simulation on the Driving Restriction Policy

We then stimulate different levels of driving restriction policy and investigate their impacts on congestion probability. We set four levels of driving restriction policy, which represents $20 \%$ of gasoline vehicles, $0 \%$ of NEVs (policy 1 , the current policy), $20 \%$ of gasoline vehicles $20 \%$ of NEVs (policy 2), $50 \%$ of gasoline vehicles, $0 \%$ of NEVs (policy 3) and 50\% of gasoline vehicles, 50\% of NEVs (policy 4) are restricted each workday of a week. Table 7 shows that with an increase in the proportion of traffic restriction, the congestion probability of the road network decrease from $21.77 \%$ to $3.93 \%$. Hence, the more NEVs facing driving restriction, the less the congestion probability will be. 
Table 7. Traffic congestion probabilities under different driving restriction policies

\begin{tabular}{|c|c|c|c|c|}
\hline Policies & $\begin{array}{l}\begin{array}{l}\text { Proportion of } \\
\text { vehicles }\end{array} \\
\text { restriction }\end{array}$ & $\begin{array}{l}\text { Proportion of } \\
\text { NEVs facing } \\
\text { restriction } \\
(\%)\end{array}$ & $\begin{array}{l}\text { Average velocity } \\
(\mathbf{k m} / \mathbf{h})\end{array}$ & $\begin{array}{l}\text { Congestion } \\
\text { probability }(\%)\end{array}$ \\
\hline Restriction Policy 1 & 20 & 0 & 27.75 & 21.77 \\
\hline Restriction Policy 2 & 20 & 20 & 27.84 & 21.45 \\
\hline Restriction Policy 3 & 50 & 0 & 34.92 & 4.23 \\
\hline Restriction Policy 4 & 50 & 50 & 35.15 & 3.93 \\
\hline
\end{tabular}

Table 7 shows the traffic congestion probabilities under different driving restriction policies. By comparing restriction policy 1 and restriction policy 3 , we find that with an increase in the proportion of traffic restriction, the congestion probability of the road network decrease from $21.77 \%$ to $4.23 \%$, the more vehicles facing driving restriction, the less the congestion probability will be. By comparing restriction policy 1 to restriction policy 2 , we find that the congestion probability of the road network decrease from $21.77 \%$ to $21.45 \%$ when NEVs are also subjected to restriction. Since the NEVs in the proportion of the total amount of motor vehicles is small (only 2.95\%), the magnitude of the reduction on congestion probability is not salient.

\section{Conclusions and Discussion}

In recent years, air pollution caused by vehicle exhaust emissions has become serious in Beijing. In order to reduce vehicle exhaust emissions and mitigate the current air pollution situation, the Beijing Municipal Government has implemented a series of policies to promote NEVs by controlling vehicles' purchasing (lottery policy) and travelling (driving restriction policy) process. Despite NEV's potential benefit on air quality, we propose that the NEV policies worsen Beijing's traffic condition by increasing congestion probabilities. Using Beijing's actual traffic statistics, we theoretically build and empirically test NEV policies' impact on Beijing's traffic congestion.

Our theoretical model shows that the increases in the proportion of newly added NEVs will lead to increases in the number of vehicles on the road network, while increased vehicles travelling on the road will increase the strain on Beijing's traffic, resulting in a decrease in the average velocity of the vehicles travelling on the roads and a rise in the congestion probability. Empirically, we investigate the impacts of NEV policies on traffic condition based on Beijing's traffic statistics. The results show that from 2014 to 2017, as the proportion of newly added NEVs increases, the number of vehicles that are allowed to travel on the road increases from 4.4768 million to 4.7692 million, and the density of the road network increases from 80.37 vehicles $/ \mathrm{km}$ to 84.58 vehicles $/ \mathrm{km}$. Consequently, the average velocity decreases from $28.31 \mathrm{~km} / \mathrm{h}$ to $27.32 \mathrm{~km} / \mathrm{h}$, and the congestion probability rises from $19.82 \%$ to $23.31 \%$. Moreover, the elasticity analysis shows a $1 \%$ increase in the proportion of newly increased NEVs will reduce the average velocity of vehicles travelling on the road by $0.1267 \mathrm{~km} / \mathrm{h}$. In addition, we conduct policy simulations both on lottery policy and driving restriction policy. The result shows that 1) the increases in proportion of newly added NEVs will lead to a decrease in average speed of traffic and a rise in the congestion probability; 2) The more vehicles facing driving restriction, the less the congestion probability will be.

Three policy suggestions could be provided based on our study: 1) we need to reevaluate the NEV policies from a comprehensive perspective. Although the generalization of the NEVs may alleviate air pollution, they also have the risk of worsening Beijing's traffic condition. Therefore, simply increase the proportion of NEVs in newly-added vehicles is questionable for both Beijing's air quality and traffic condition in the long run; 2) Policy simulations show that if the NEVs are also subjected to the driving restriction policy, thus, constraining NEVs from driving each workday during the week, will substantially lower the probability of traffic congestion. Therefore, we suggest that NEVs should also be constraint by driving restriction policy (or with a lower degree); 3) We suggest that the NEV policies should be combined with other traffic policies, such as congestion charges, in order to improve air quality without worsening traffic condition.

Finally, this research also has limitations: 1) in our paper, one of the key variables, the length of road constructed in Beijing, is predicted based on the existing annual data, which has to be adjusted to the significant acceleration of road construction for future prediction; and 2) we calculate the proportion of vehicles traveling on the road based on 2015 data and assume that this proportion remains stable during the research period. However, this proportion may be affected by several factors in practice, such as the development of public transport. In the future, these limitations also guide the directions for future research. Furthermore, we will extend the current research by seeking the most 
cost-effective proportion of newly added NEVs by conducting cost-benefit analysis.

\section{Acknowledgement}

The authors thank the support by the National Social Science Foundation of China (Grant No.16BGL163).

\section{References}

Bando, M. et al. (1995). Dynamical Model of Traffic Congestion and Numerical Simulation. Journal of Physical Review E, 51(2), 12082-12085. https://doi.org/10.1103/PhysRevE.51.1035

Brand, C. et al. (2017). Modeling the uptake of plug-in vehicles in a heterogeneous car market using a consumer segmentation approach. Journal of Transportation Research Part A: Policy and Practice, 97, 121-136. http://dx.doi.org/10.1016/j.tra.2017.01.017

Campbell, A. R. et al. (2012). Identifying the early adopters of alternative fuel vehicles: A case study of Birmingham, United Kingdom. Journal of Transportation Research Part A: Policy and Practice, 46(8), 1318-1327. https://doi.org/10.1016/j.tra.2012.05.004s

Cui, C.Y. (2015) A Study on Urban Traffic Congestion Probability Estimation Based on Cumulative Logistic Model. M.S. Thesis, Beijing Jiaotong University, China.

Graham-Rowe, E. et al. (2012). Mainstream consumers driving plug-in battery-electric and plug-in hybrid electric cars: A qualitative analysis of responses and evaluations. Journal of Transportation Research Part A: Policy and Practice, 46(1), 140-153. https://doi.org/10.1016/j.tra.2011.09.008

Guo, S. et al. (2014). Elucidating Severe Urban Haze Formation in China. Journal of Proceedings of the National Academy of Sciences of the United States of America, 111(49), 17373-17378. https://doi.org/10.1073/pnas.1419604111

Guo, Z. Y. (2017). Health Insurance and the Demand for Medical Care: a Case Study from China. Agricultural Development, 4(1), 8-13.

He, H. et al. (2012). SO2 over Central China: Measurements, Numerical Simulations and The Tropospheric Sulfur Budget. Journal of Geophysical Research: Atmospheres, 17(D16), 812-819. https://doi.org/10.1029/2011JD016473

Horvitz, E. J. et al. (2012). Prediction, Expectation, and Surprise: Methods, Designs, and Study of a Deployed Traffic Forecasting Service. Proceedings of the Twenty-First Conference on Uncertainty in Artificial Intelligence. (UAI2005).

Hoshino, T. et al. (2011). Analysis of Traffic Congestion by Considering Merging on Entry Lines in Transportation System. Journal of Electronics \& Communications in Japan, 131, 1059-1067.

Huang, R. J. et al. (2014). High Secondary Aerosol Contribution to Particulate Pollution During Haze Events in China. Nature, 514(7521), 218-222. https://doi.org/10.1038/nature13774

$\mathrm{Li}, \mathrm{M}$. et al. (2017). Improving the electrification rate of the vehicle miles traveled in Beijing: A data-driven approach. Journal of Transportation Research Part A: Policy and Practice, 97, 106-120. https://doi.org/10.1016/j.tra.2017.01.005

Liu, M. F. \& Liu, Y. F. (2015). Research on Constructing Urban Green Transportation System Based on System Dynamics: Taking Shenzhen City as an Example. Journal of Science-Technology and Management, 17(5), 6-13.

Liu, Y. et al. (2009). Source Apportionment of Polycyclic Aromatic Hydrocarbons (PAHs) in Surface Sediments of the Huangpu River, Shanghai, China. Journal of Science of the Total Environment, 407(8), 2931-2938. https://doi.org/10.1016/j.scitotenv.2008.12.046

Munford, L. A. (2017). The impact of congestion charging on social capital. Journal of Transportation Research Part A: Policy and Practice, 97, 192-208. https://doi.org/10.1016/j.tra.2017.01.018

Pasquale, C. et al. (2015). Two-class Freeway Traffic Regulation to Reduce Congestion and Emissions via Nonlinear Optimal Control. Journal of Transportation Research Part C: Emerging Technologies, 55, 85-99. https://doi.org/10.1016/j.trc.2015.01.013

Schuitema, G. et al. (2013). The role of instrumental, hedonic and symbolic attributes in the intention to adopt electric vehicles. Journal of Transportation Research Part A: Policy and Practice, 48, 39-49. https://doi.org/10.1016/j.tra.2012.10.004 
Treiber, M. et al. (2013). Traffic Flow Dynamics: Data, Models and Simulation. Journal of Physics Today, 67(3), 54-54.

Wang, J. et al. (2015). Predictability of Road Traffic and Congestion in Urban Areas. Journal of PloS One, 10(4), e0121825. https://doi.org/10.1371/journal.pone.0121825

Xie, X. Y. et al. (2011). The Social Cost of Transportation Congestion in Beijing. Journal of China Population Resources and Environment, 01, 28-32.

Xu, T.Y. (2014). A Study on the System Dynamics of Beijing's Traffic Policy. M.S. Thesis, Beijing Jiaotong University, China.

Yang, J. et al. (2014). A review of Beijing' s Vehicle Registration Lottery: Short-term Effects on Vehicle Growth and Fuel consumption. Journal of Energy Policy, 75, 157-166. https://doi.org/10.1016/j.enpol.2014.05.055

Zhang, P. et al. (2015). A Method for Estimating Road Congestion Probability and Its Application in Urban Traffic Operation Evaluation. Journal of Transportation Systems Engineering and Information Technology, 15(6), 161-169.

Zhang, Y. et al. (2015). Modelling of Sustainable Development of Urban Traffic Based on Vehicle Policy. Journal of Highway and Transportation Research and Development, 32(6), 142-147.

Zhao, L. et al. (2005). Onset of Traffic Congestion in Complex Networks. Journal of Physical Review E Statistical Nonlinear \& Soft Matter Physics, 71(2), 026125. https://doi.org/10.1103/PhysRevE.71.026125

\section{Notes}

Note 1. Data source: Beijing Municipal Environmental Protection Bureau

Note 2. Link: http://zhengwu.beijing.gov.cn/ghxx/qtgh/t1359600.htm

Note 3. Data source: Lottery Index for Passenger Cars Decreases Year by Year, and the License Auction System May be Adopted, China Business Journal, May 16, 2016

Note 4. Data source: Analysis of the Traffic of Major Cities in China

Note 5. Data source: Beijing Transport Annual Report 2014

Note 6. Data source: it is assumed that the maximum traffic flow refers to the situation where vehicles touch each other, where all cars have an average length of $5 \mathrm{~m}$

Note 7. Data source: Beijing Statistical Yearbook 2014

Note 8. Data source: Beijing Transport Annual Report 2014

Note 9. Data source: we suppose the number of new energy vehicles is 0 in 2013 for there is no new energy vehicle index this year

Note 10. Data resource: Beijing Transport Annual Report 2012. From 2011, Beijing began to implement the lottery policy. So, we believe that the average speed of the early peak in Beijing in 2011 is the velocity of severe congestion.

Note 11. Data source: Beijing Statistical Yearbook 2014-2016

Note 12. Data source: Zhang et al., 2015 


\section{Appendix}

Table 1. The number of motor vehicles and scrapped vehicles in Beijing 2013-2015 (Note 11)

\begin{tabular}{|c|c|c|c|c|c|}
\hline Year & $\begin{array}{l}\text { Number of motor } \\
\text { vehicles at the } \\
\text { beginning of the } \\
\text { year (ten thousand) }\end{array}$ & $\begin{array}{l}\text { Number of } \\
\text { added v } \\
\text { this year } \\
\text { thousand) }\end{array}$ & $\begin{array}{l}\text { f newly Number of } \\
\text { vehicles vehicles at the } \\
\text { (ten the year } \\
\text { thousand) }\end{array}$ & $\begin{array}{l}\text { motor Number } \\
\text { end of scrapped } \\
\text { (ten this year } \\
\text { thousand) }\end{array}$ & $\begin{array}{l}\text { of The proportion } \\
\text { vehicles of scrap } \\
\text { (ten }\end{array}$ \\
\hline 2013 & 520 & 24 & 543.7 & 0.3 & $0.06 \%$ \\
\hline 2014 & 543.7 & 24 & 559.1 & 8.6 & $1.54 \%$ \\
\hline 2015 & 559.1 & 13 & 569.1 & 3 & $0.53 \%$ \\
\hline average & 540.9 & 20.3 & 557.3 & 4.0 & $0.71 \%$ \\
\hline
\end{tabular}

Table 2. The TTI dynamic distribution feature vectors of different road sections in the inner ring of the West $2^{\text {nd }}$ Ring (Note 12)

\begin{tabular}{lllll}
\hline Road sections & A & B & C & D \\
\hline 17502 & -0.8753 & 3.1698 & 0.3289 & -0.0553 \\
17653 & -0.9369 & 3.4964 & 0.3126 & -0.0581 \\
18391 & -0.8434 & 2.9012 & 0.3462 & -0.0351 \\
20554 & -0.7745 & 2.3332 & 3.0300 & -0.1148 \\
29283 & -0.8568 & 2.9993 & 0.3691 & -0.0341 \\
29325 & -0.9060 & 3.2230 & 0.5659 & -0.0473 \\
29326 & -0.8734 & 3.0672 & 2.1770 & -0.1191 \\
29385 & -0.8504 & 2.8140 & 0.6896 & -0.0512 \\
29409 & -0.9160 & 3.4156 & 1.4300 & -0.1233 \\
29416 & -0.8668 & 3.0750 & 0.7737 & -0.0660 \\
29585 & -0.7177 & 2.4515 & 0.8731 & -0.0770 \\
29586 & -0.9080 & 3.4359 & 0.4679 & -0.0673 \\
32604 & -0.6394 & 2.1382 & 0.9131 & -0.0743 \\
51103 & -0.7218 & 2.3189 & 0.4846 & -0.0507 \\
19594 & -0.9394 & 3.4806 & 0.3214 & -0.0623 \\
\hline
\end{tabular}

